Journal of Computer Science 6 (10): 1170-1176, 2010

ISSN 1549-3636

(C) 2010 Science Publications

\title{
Tacit Knowledge Codification
}

\author{
Marzanah A. Jabar, Fatimah Sidi and Mohd. Hasan Selamat \\ Department of Information System, \\ Faculty of Science Computer and Information Technology, \\ University Putra Malaysia, 43400 UPM Serdang Selangor, Malaysia
}

\begin{abstract}
Problem statement: In managing knowledge and competencies as a strategic advantage to an organization, there are difficulties in capturing, storing, sharing and reusing all this knowledge. Researchers have agreed that assessing tacit knowledge is difficult because knowhow of an employee are elusive and what more to assess them. It is compounded when employees leave the organization or become unavailable due to their mobility within the organization. As a result various approaches to collection and codification of knowledge have emerged. One of the most important approaches to emerge is knowledge management. Approach: In this study, we presented Knowledge Extract, Profiling and Sharing Network (KEPSNet), framework to facilitate the codification knowledge and competencies management adapting knowledge management processes in capturing, storing, sharing and reusing knowledge and competencies. Results: We enhanced these processes autonomously by capturing knowledge and competencies in tacit and explicit form from members of group project implementation in the form of concept maps and managed, according to knowledge management process. A case study in a software development group setting was evaluated and results of knowledge management processes output generated from KEPSNet prototype are compared with the result from the project manager in managing the project based. Two sets of questionnaires were given to the group members before and after implementing KEPSNet. Conclusion/Recommendations: The result of the evaluation validates the viability of the key concept presented. Codification of tacit knowledge has resulted in the codified knowledge and competencies recognized.
\end{abstract}

Key words: Knowledge management, codification, competencies, group knowledge, tacit knowledge

\section{INTRODUCTION}

Group project implementation is a situation where there is a common purpose (s) and shared goal (s) among its member. Due to technology advancement, group knowledge from members of various expertise and experiences can be tapped and learned. Communication between members is facilitated and group knowledge can be managed. To facilitate the capture, sharing and reuse of knowledge and its management, we propose a group knowledge management environment. Group member may share their knowledge, experiences, ideas and all the necessary knowledge to execute their tasks.

Many researchers have acknowledged the limitations of current approaches and techniques to managing knowledge that relates to and arises from projects (Asprey, 2004; Laudon and Laudon, 1997; McGee and Prusak, 1993; Sor, 2004).
There are not only difficulties in capturing, storing, sharing and reusing all this knowledge but much of it is never 'produced', since there are no mechanisms or processes exist to foster the social interaction required to give any shape or form to it. Therefore there is a need to promote knowledge creation, sharing and reuse, along with the tools to support such process. For this purpose a framework for group project implementation knowledge and competencies management was developed. This study will focus and discuss only on the codification of knowledge and competencies only.

Managing knowledge has been a frequently studied research topic. For example in the Knowledge Management for Concurrent Design (CACIC) by Barthes and Tacle (2002), Corporate Memory Management through Agents (CoMMA) project by Bergenti et al. (2002), Knowledge intelligent Conversational Agent (KinCA) by Roda et al. (2003), Recommender System by Stenmark (2000), Collaborative Agent Interaction and

Corresponding Author: Marzanah A. Jabar, Department of Information System,

Faculty of Computer Science and Information Technology, University Putra Malaysia, Malaysia 
synchronization (CAIRO) by Nonaka and Takeuchi (1995) and Framework for Distributed Organizational Memories (FRODO) by Abecker et al. (2003). Most of the research issues discussed in these researches illustrates how computer based system has contributed towards the process of locating, retrieving, delivering and dissemination of information in facilitating knowledge processes.

As most of KM technologies emerged from document-centric approaches and support KM cycle such as classifying, storing and retrieval of knowledge, Pena-Mora et al. (2000) states that there exist the limitation related to the management of tacit knowledge. There is also the limitation in taking into account their interaction, competencies, interest and motivation. Since there is an increasing interest in the tacit knowledge in knowledge management and not much has been said about conceptualizing individual competence with knowledge management as discussed in (Mulder and Whitely, 2007; Van der Spek and Spijkervet, 1997) we proposed KEPSNet in extending the capabilities to managed knowledge and competencies to reflect group expertise and organization know how.

Group project implementation is an act of collaborative knowledge activities and problem solving tasks. Knowledge is captured by project data and information or in face-to-face interactions, individual actions and problem solving actions, task performed, hands-on experimentation and communications within group members. Problem solving occurs in the context of the activities the group perform and the knowledge they possess and these activities tend to occur in steps taken by the project. Knowledge processes such as project workshops, project progress meetings are activities that take place between group members. Through this interaction knowledge can be captured. This research implies that knowledge is a thing that can be located and manipulated as an object, which is possible to capture, distribute and manage. This means we can manage it through codification, creation, storage and reuse in computer-based knowledge repositories.

\section{MATERIALS AND METHODS}

We present KEPSNet framework by adapting the knowledge management process based on the work of Dynamic theory of Organizational Knowledge Creation by Nonaka and Takeuchi (1995) and Mochol et al. (2006); (ii) The intangible asset as the source of value by Sveiby (1997); Work on leveraging existing codified knowledge assets by Wiig (1994) and Mentzas et al. (2003) and (iv) Methods for identifying strategic knowledge by Grundstein and Barthes (1999). The
KEPSNet framework in Fig. 1, is described in the following stages of knowledge management process, which are (i) Retain, where knowledge is captured, to avoid loss of knowledge how of an expert in the group (ii) Retrieve, where knowledge is compared and matched for profiling and personalization purposes so as to exploit the experience acquired from past projects and to keep some lessons from past, in order to avoid reinventing the cycle and (iii) Reuse, where knowledge recommendation and networking are generated according to the user profile based on profile similarities, to enable the exploit of expertise knowledge, where a directory of expertise and associated know how will enhance the organization ability to react and adapt to changes and to improve staff mobilization in an organization.

The main goal of KEPSNet is to support the management of knowledge and competencies. KEPSNet identifies three main KM processes namely the Knowledge Retain, Knowledge Retrieve and Knowledge Reuse. From these processes, three knowledge services were introduced: Knowledge Capture and Structuring, Profiling and Personalization and Knowledge Recommendation and Networking. From these services, the following functionalities were offered to support the knowledge processes in managing group knowledge and competencies:

- Obtain user input-provide interface for the user to explore group knowledge through menu of the portal

- Present information-provide interface for the user to seek the knowledge network and knowledge available personalized to the user

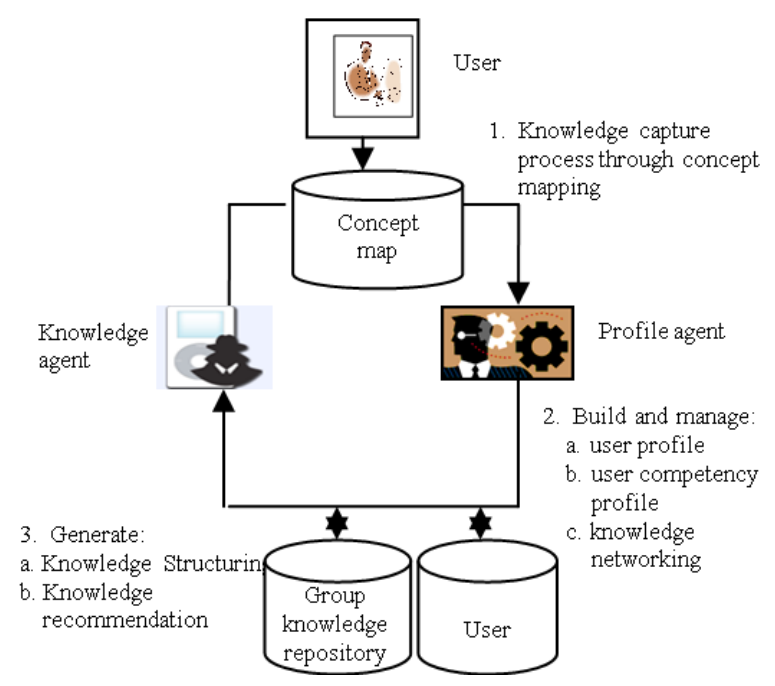

Fig. 1: KEPSNet framework 


\section{J. Computer Sci., 6 (10): 1170-1176, 2010}

- Access available knowledge-retrieve existing group knowledge from the repository and who knows what in the group

- Capture knowledge-provide an interface for the user to submit the concept maps

- Register user profile-autonomous and dynamic creation of user profile

- Recommendation-autonomous and dynamic knowledge recommendation based on user profiling and personalization

- Update knowledge to user profile-autonomous and dynamic update to user profile

- Update competencies to user profile-autonomous and dynamic update to competencies scale profile

This study will only focus on the codification of knowledge and competencies of the group project members in the discussion of the following functionalities.

Knowledge capture and structuring: Knowledge capture process using concept map are designed to tap into a person's cognitive structure and externalize concepts and propositions (Laudon and Laudon, 1997). Users know how or expertise's are captured without asking the user explicitly, but through knowledge captured in the concept maps. Concept Maps captured are submitted to KEPSNet and exported to the knowledge repository in XML format. Concept Maps submitted is identified as the Knowledge Attributes of the group project and is grouped into Knowledge Activities Profile. Knowledge Activities Profile concept map is used for the Project Manager to construct the knowledge of the activities in a conceptualized concept form. The resource person or the experts or known as the resource person, were identified and acknowledged when they contribute knowledge, annotated with links to the topic and the resource person. To have an effective mechanism to manage knowledge from the group it is best to build knowledge structures based on some classification schemes, ontologies, or some other forms of knowledge representation that will make it easy to store, organize, access and analyze (Hansen et al., 1999; Koehn and Abecker, 1997; Leake et al., 2003; Lindgren et al., 2003). One of the ways to organize the knowledge is by splitting the information groups into categories and structuring the information in each category. After categories are created, it is associated with concepts from the concept map in the knowledge repository in the following structure: Knowledge asset (list of knowledge contribution during project implementation), Knowledge activities profile (description of knowledge activities during group implementation), user profile (description of the expertise profile), user competencies profile (level of competencies) and knowledge domain (description of the knowledge domain understood and agreed by the group).

Profiling and personalization: Profiling in KEPSNet grouped together people on certain basis as discussed by Douflou et al. (2004) and Mochol et al. (2006). The concept similarity algorithm in the profiling technique, performed classification automatically user profiles online and quickly. Agent is used in profiling to enable proactive profiling for knowledge networking purposes. The user profiles and user competencies profiles were generated using learning technique (clustering) in identifying patterns in concepts generated. Clustering is used as a type of learning (Duda et al., 2000) and similarities between profiles were used to detect common areas of knowledge by each user's profiles. Similarity measures based concept matching from the work of Marshall and Madhusudan (2004) are applied as it is suitable for concept maps. User profile matching are generated by Profile Agent which creates and manages the profile of each users, each profile is then compared and the agent will proactively anticipate the group and knowledge networking based on similar expertise. In personalization we used "Case Based Reasoning", which is capable of identifying the same or similar concept maps available in the repository and generates new knowledge based on already existing knowledge. This module has the following functionality where similar cases and the result of the CBR is a matrix ordered with assign ranked similarities matching algorithm. The algorithm uses the similarity matrix to generate the mapping. The higher the value in the matrix corresponds to the most similar between the two concepts. Data from all users' profiles are continuously matched and ranked by the profile agent for recommendation purpose. The higher the number shows the more similar the profiles are and the knowledge networking, will then grouped them accordingly. Based on these groups users of similar expertise can be identified and grouped together.

In order to demonstrate the application KEPSNet on knowledge and competencies codification, a case study on a software application development at the Institute of Multimedia and application in University Putra Malaysia is presented. A test group comprises of two project managers and project members of an application development group, were selected. The test group was briefed on the evaluation tasks. They were asked to fill in the Questionnaire on how they manage 
and codify knowledge and competencies before using KEPSNet. They were then trained to use concept map tool for externalizing knowledge from the group and were briefed on KEPSNet Portal functionalities. Another set of Questionnaire were given to be answered after completing the evaluation using KEPSNet prototype. The results from the Questionnaires were then analyzed.

\section{RESULTS AND DISCUSSION}

KEPSNet had utilized the approach and uses 'Concept Map' tool in its effort to capture knowledge from group members. Concept Maps of project activities during various workshops from the project were captured, transformed, grouped and retained in the group knowledge repository as shown in Table 1 as a codification strategy for knowledge and competencies. It describes the knowledge attributes structures build from the concept maps. There are six structures of knowledge identified as knowledge captured for the group knowledge repository.

Knowledge about group member expertise were presented and published through the Portal according to the field of expertise of the group using concepts based on the knowledge domain discipline. By having the knowledge of the expertise profiles made known to the public it will increase the awareness and promote the group member and their work beyond the project community and the knowledge about their expertise can be consolidated into their curriculum vitae.

Competencies profile in Fig. 2, identified the competencies based on the key concepts of user's knowledge contribution and then matched against the key concepts of the group knowledge domain. The scale of 0 to 1 , denotes the level of similarities to the knowledge domain, the higher the number dictates the similar knowledge of the expertise to the knowledge domain. The ranking are used to form some understanding on the competencies of an expert based on their knowledge, task analysis and their abilities (Haerem, 1998).

Figure 3, described the key concepts associated with the explicit knowledge, while Fig. 4, listed the explicit knowledge as described in the repository, which describes how knowledge can be manage: Retain, retrieve and reuse within the group and organization.

Knowledge activities in Table 2 refers to collection of key concepts in a group task activities concept map. The concepts represent knowledge of the task activities from the group project.
Table 1: Group knowledge description repository

Knowledge capture inventory Knowledge description

Expertise profile

Competencies profile

Description of the expertise profile in the form of concepts.

Level of competencies in the scale of (0-1).

Knowledge asset

List of knowledge contribution during project implementation.

Knowledge asset repository Knowledge contribution in the group knowledge repository.

Knowledge activities

Description of knowledge activities during group implementation.

Knowledge domain

Description of the knowledge domain understood and agreed by the group.

Table 2: Knowledge activities

\begin{tabular}{|c|c|c|c|}
\hline Design.cmap & $\begin{array}{l}\text { Design } \\
\text { specification.cmap }\end{array}$ & $\begin{array}{l}\text { Project } \\
\text { publication.cmap }\end{array}$ & $\begin{array}{l}\text { System } \\
\text { development } \\
\text { process.cmap }\end{array}$ \\
\hline $\begin{array}{l}\text { Conceptual } \\
\text { database design }\end{array}$ & Standards & $\begin{array}{l}\text { Questionnaires } \\
\text { report }\end{array}$ & $\begin{array}{l}\text { Quality } \\
\text { assurance }\end{array}$ \\
\hline Coding & UML & Research & $\mathrm{V}$ model \\
\hline Development tool & IEEE & Questionnaires & Guideline \\
\hline OO design & Design specification & Data & User interface \\
\hline Review & Design methodology & Project publication & Progress \\
\hline User requirement & System development & Paper presentation & Process \\
\hline Design & Modeling & Paper guidelines & Draft \\
\hline Rational rose & System design & Analysis & Review \\
\hline Programming & & Publication & $\begin{array}{l}\text { Project } \\
\text { management }\end{array}$ \\
\hline Database & & & $\begin{array}{l}\text { System } \\
\text { development } \\
\text { process }\end{array}$ \\
\hline Configuration & & & Project report \\
\hline Hardware & & & Monitor \\
\hline $\begin{array}{l}\text { Interaction } \\
\text { diagram }\end{array}$ & & & $\begin{array}{l}\text { System } \\
\text { requirement }\end{array}$ \\
\hline
\end{tabular}

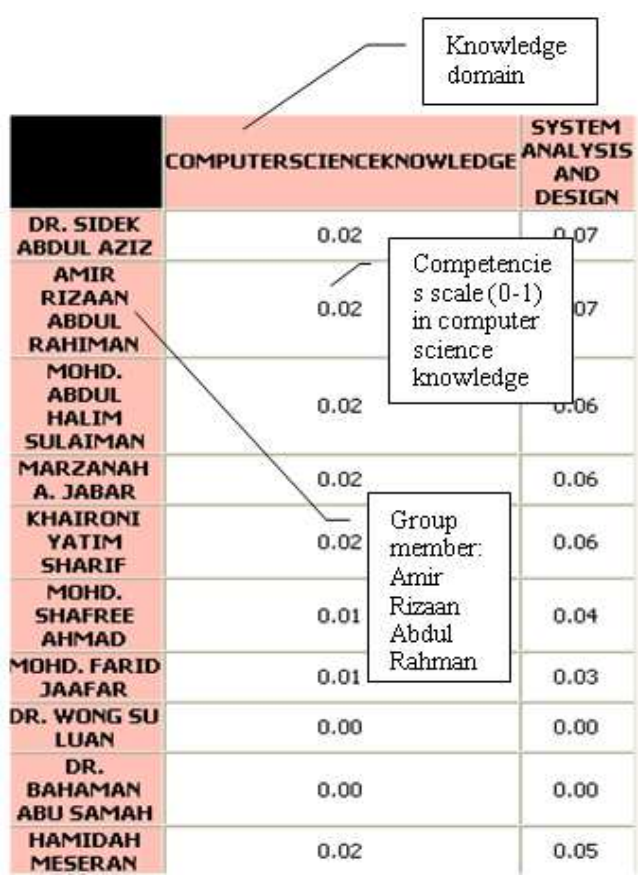

Fig. 2: Competencies profile 


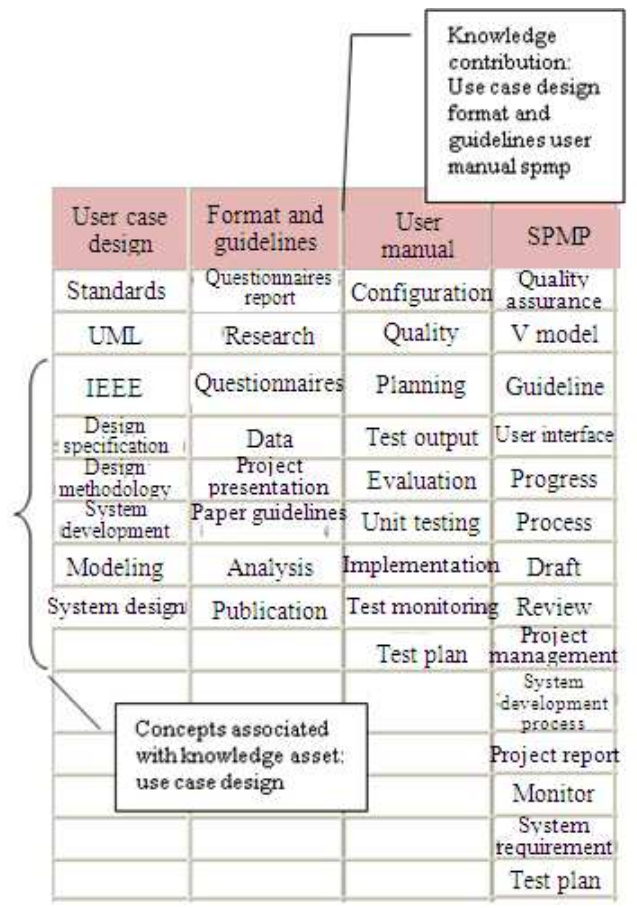

Fig. 3: Knowledge asset

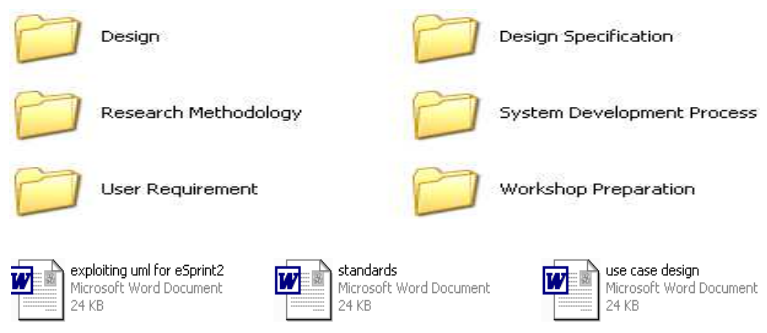

Fig. 4: Knowledge asset repository

Knowledge domain in Fig. 5, described the area of knowledge the group agrees on and is represented as list of key concepts, which are the terms that the group agrees to use in describing their knowledge. It helps the group member to use the same words for expressing themselves and thus understanding themselves more easily. Knowledge domain is used for the similarity matching algorithm and clustering of automated extraction of competencies from the concept maps for profiling and personalizing knowledge reuse and retrieve.

Two sets of questionnaires were given to the respondents. First set of questionnaire were asked for the current practice implementation, while the second set were asked after the completion of the tasks using KEPSNet Portal. For the analysis of knowledge capture process, questions from $\mathrm{Q} 3, \mathrm{Q} 4$ and $\mathrm{Q} 5$ were asked.

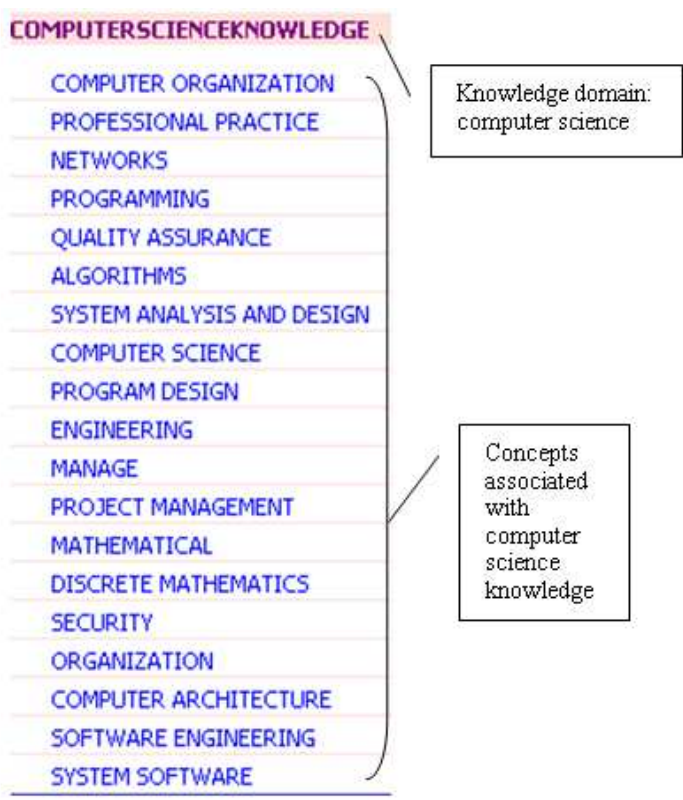

Fig. 5: Knowledge domain

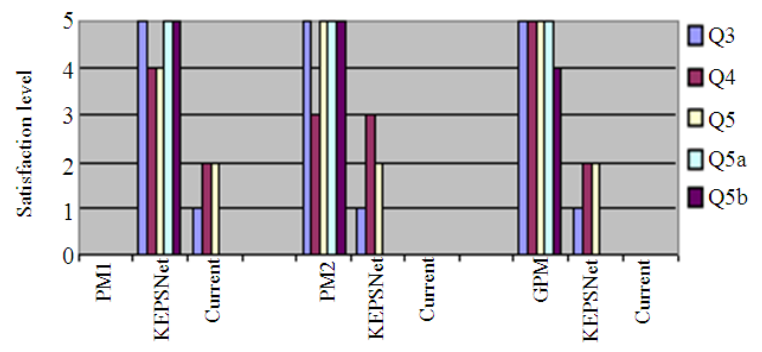

Fig. 6: Evaluation of knowledge capture process for KEPSNet versus current implementation

Respondents were also asked on the use of Concept Map as the knowledge capture approach for KEPSNet implementation Q5a and Q5b:

Q3 Support knowledge capture from project team member

Q4 Easy and flexible

Q5 Support various format of knowledge capture

Q5a Concept Map (CM) is an effective tool in making knowledge available to others

Q5b Will use (CM) for other knowledge intensive activities

The measures of the respondent's satisfaction level of the knowledge capture process, from the above questions were displayed in Fig. 6. The chart in Fig. 6, shows the respondents satisfaction level on group knowledge capture process of KEPSNet as compared to the current implementation for knowledge capture. 


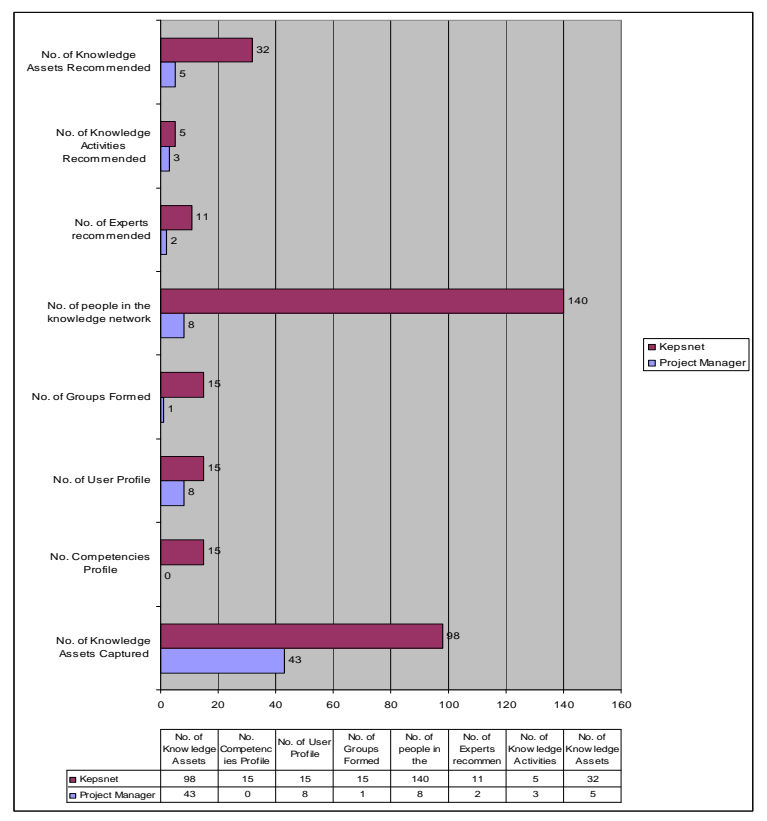

Fig. 7: Results of the knowledge process activities

It can be clearly seen that KEPSNet performed better than the current practices in the knowledge capture process. All three respondents gave a fair (3) to very satisfied (5) ranking for knowledge capture (Q3), the knowledge capture ease and flexibility (Q4) and for the support of various format (Q5) in knowledge capture process. The current implementation did not performed satisfactorily in knowledge capture process. This can be explained by the comments from the respondents as there is no proper knowledge capture process or any initiative in the formation of Knowledge Repositories for the current practice.

On the question regarding concept map approach for knowledge capture process specifically for KEPSNet, in Q5a and Q5b, KEPSNet attained very satisfactorily responses from all respondents. Based on the comments given by them during the questionnaire session and also from the responses; all of the participants were receptive to the approach that this is one of the effective approaches in making knowledge tangible to others and can be chosen as the knowledge capture approach for any other group knowledge management processes.

The results of the knowledge capture and codification from KEPSNet are compared with values extracted from project manager without using KEPSNet. The results in Fig, 7 showed the knowledge process activities output generated from KEPSNet and compared with values extracted from the user (Project Manager). The knowledge process activities compared are the numbers of knowledge assets captured, numbers of user profiles created, numbers of competencies profiles created, numbers of knowledge networking group formed and numbers of expertise, knowledge activities and knowledge assets recommended.

It clearly emerged from the findings that KEPSNet is able to manage tacit knowledge and competencies. Concept map as a method of tacit knowledge capture have shown that tacit knowledge can be capture as knowledge assets. Knowledge assets captured are defined as files saved in the folders for the project. There are 98 knowledge assets folders captured by KEPSNet as compared to 43 files in the folders recorded as knowledge contributed and captured from the project members without using KEPSNet. Competencies captured are realized as 15 competencies profiles generated associated with the tacit knowledge captured. This finding indicated that recognition could be given and expertises were measured as each competencies profile are ranked in the number of $0-1$. The ranking of competencies has provided a metric where it can be used for evaluation purposes.

\section{CONCLUSION}

This study presents the implementation of KEPSNet framework in managing knowledge in a group project. KEPSNet has shown that tacit knowledge can be captured where group members can represent and encode their knowledge using concept mapping and further structured it as knowledge captured in a repository. KEPSNet contribution is that it demonstrates how knowledge and competencies can be managed, acknowledgement of expertise and referral of the expert for knowledge sharing. Recent advancements which include the use of intelligent agent (Roda et al., 2003), are some of the future study and possibilities that can be looked into in the improvement and enhancement into KEPSNet decision making capabilities.

\section{REFERENCES}

Abecker, A., A. Bernardi and L. van Elst, 2003. Agent technology for distributed organizational memories-the FRODO project. Proceeding of the International Conference on Enterprise Information Systems, (EIS'03), IEEE Press, France, pp: 3-10.

Asprey, L., 2004. Information strategies: Are we aligning the business case with enterprise planning? Rec. Manage. J., 14: 7-13. DOI: $10.1108 / 09565690410528893$ 
Barthes, J.A. and C.A. Tacle, 2002. Agent Supported portals and knowledge management in complex $\mathrm{R}$ and D projects. Comput. Ind., 48: 3-6. DOI: 10.1016/S0166-3615(02)00006-4

Bergenti, F., A.P., G. Rimassa and P. Turci, 2002. CoMMA a multi-agent systems for corporate memory management. Proceedings of the 1st International Joint Conference on Autonomous Agents and Multiagent Systems, July 15-19, ACM Press, Bologna, Italy, pp: 1039-1040. DOI: 10.1145/545056.545066

Douflou, J., K. Hermans, B. Vandermeulen and B.D. Moor, 2004. User profile integration in knowledge management systems. Proceeding of the International Conference on Competitive Manufacturing, (COMA'04), Katholieke Universiteit Leuven, Belgium, pp: 1-6.

Duda, R.O., P.E. Hart and D.G. Stork, 2000. Pattern Classification. 2nd Edn., Wiley-Interscience, New York, ISBN: 13: 9780471056690, pp: 654.

Grundstein, M. and J.P. Barthes, 1999. An Approach to Enterprise Knowledge Capitalization? In Knowledge Management. Enterprise, Network and Learning. In: Advances in Knowledge Management, Schreinemakers, J. and J.P. Barthès (Eds.). Ergon Verlag, Germany, pp: 151-159.

Haerem, T., 1998. Norsk konferanse for organisasjoners bruk av IT. NOKOBIT. http://www.nokobit.no/

Hansen, M., N. Nohria and T. Thierney, 1999. What's your strategy for managing knowledge? Harvard Bus. Rev., 77: 106-118.

Koehn, O. and A. Abecker, 1997. Corporate memories for knowledge management in industrial practices: Prospect and challenges. J. Univ. Comput. Sci., 3: 929-957.

Laudon, K.C. and J.P. Laudon, 1997. Management Information Systems: New Approaches to Organisation and Technology. 5th Edn., PrenticeHall, Englewood Cliffs, NJ., ISBN: 13: 9780138577230, pp: 693.

Leake, D.B., A. Maguitman, T. Reichherzer, A.J. Canas and M. Carvalho et al., 2003. Aiding knowledge capture by searching for extensions of knowledge models. Proceedings of the 2nd International Conference on Knowledge Capture, Oct. 23-25, ACM Press, Sanibel Island, FL., USA., pp: 44-53.

Lindgren, R., D. Stenmark and J. Ljungberg, 2003. Rethinking competence systems for knowledgebased organizations. Eur. J. Inform. Syst., 12: 18-29. DOI: $10.1057 /$ palgrave.ejis.3000442

Marshall, B. and T. Madhusudan, 2004. Element matching in concept maps. Proceedings of the 4th ACM/IEEE-CS Joint Conference on Digital Libraries, July 7-11, ACM Press, Tucson, Arizona, USA., $\quad$ pp: 186-187. DOI: 10.1109/JCDL.2004.1336117
McGee, J. and L. Prusak, 1993. Managing Information Strategically. 1st Edn., John Wiley and Sons, New York, ISBN: 0471575445, pp: 272.

Mentzas, G.N., D. Apostolou, A. Abecker and R. Young, 2003. Knowledge Asset Management. 1st Edn., Springer, London, ISBN: 13: 9781852335830 , pp: 224.

Mochol, M., E. Paslaru and B. Simperl, 2006. Practical guidelines for building semantic eRecruitment applications. Proceeding of the International Conference on Knowledge Management, (KM'06), IEEE Press, Austria, pp: 1-8.

Mulder, U. and A. Whitely, 2007. Emerging and capturing tacit knowledge: A methodology for a bounded environment. J. Knowl. Manage., 11: 68-83. DOI: $10.1108 / 13673270710728240$

Nonaka, I. and H. Takeuchi, 1995. The KnowledgeCreating Company: How Japanese Companies Create the Dynamics of Innovation. 1st Edn., The Oxford University Press, New York, ISBN: 13: 9780195092691, pp: 304.

Pena-Mora, F., K. Hussein and S. Vadhvkar, 2000. CAIRO: A concurrent engineering environment for virtual design teams. Artif. Intel. Eng., 14: 203-219. DOI: 10.1016/S0954-1810(00)00016-9

Roda, C., A. Angehrn, T. Nabeth and L. Razmerita, 2003. Using conversational agents to support the adoption of knowledge sharing practices. Interact. Comput., 15: 57-89.

Sor, R., 2004. Information technology and organizational structure-vindicating theories from the past. Manage. Dec., 42: 316-329.

Stenmark, D., 2000. Enabling conditions for organizational knowledge creation. Proceedings of WebNet World Conference on the WWW and Internet, (WWWI'00), San Antonio, TX., pp: 501-506.

Sveiby, K.E., 1997. The New Organization WealthManaging and Measuring Knowledge-Based Assets. 1st Edn., Berret-Koehler, San Francisco, ISBN: 13: 9781576750148, pp: 275.

Van der Spek, R. and A. Spijkervet, 1997. Knowledge Management: Dealing Intelligently with Knowledge. In: The Knowledge Management Network, Liebowitz, J. and L. Wilcox (Eds.). CRC Press, New York, pp: 69-87.

Wiig, K.M., 1994. Knowledge Management Methods: Practical Approaches to Managing Knowledge. 1st Edn., Schema Press, Arlington, Texas, ISBN: 13: 9780963892522, pp: 490. 